\title{
Thermal Insulation of Plastic Waste Brick Composite with Rice Husk and Sawdust
}

\author{
Yayi Arsandrie*, Dhani Mutiari, Nur Rahmawati Syamsiyah, Suharyani, Saidah Aliyatul Himmah
}

Study Programme of Architecture, Faculty of Engineering, Universitas Muhammadiyah Surakarta (UMS), Indonesia

Received June 14, 2020; Revised December 8, 2020; Accepted December 22, 2020

\section{Cite This Paper in the following Citation Styles}

(a): [1] Yayi Arsandrie, Dhani Mutiari, Nur Rahmawati Syamsiyah, Suharyani, Saidah Aliyatul Himmah, "Thermal Insulation of Plastic Waste Brick Composite with Rice Husk and Sawdust," Civil Engineering and Architecture, Vol. 8, No. 6, pp. 1283 - 1289, 2020. DOI: 10.13189/cea.2020.080612.

(b): Yayi Arsandrie, Dhani Mutiari, Nur Rahmawati Syamsiyah, Suharyani, Saidah Aliyatul Himmah (2020). Thermal Insulation of Plastic Waste Brick Composite with Rice Husk and Sawdust. Civil Engineering and Architecture, 8(6), 1283 - 1289. DOI: 10.13189/cea.2020.080612.

Copyright $\odot 2020$ by authors, all rights reserved. Authors agree that this article remains permanently open access under the terms of the Creative Commons Attribution License 4.0 International License

\begin{abstract}
The growth of plastic waste increases every year in almost all countries in the world, including Indonesia. One of the most potential ways of utilizing plastic waste is in the field of building construction. Plastic, and other agriculture waste such as sawdust and rice husk, had been investigated in some previous researches to be used in the innovation of building materials. This research aims to find the composition of plastic waste which was combined with sawdust and rice husk to become an alternative brick material as thermal insulation for the building. This research used two methods; the first was to produce some samples from plastic waste materials with sawdust or rice husk and the second was to measure the thermal characteristics on those sample materials. Sampling was conducted by using variations of the composition of the mixture which was then tested for its ability to absorb heat during the day and night. Measurement results showed that the percentage of $70 \%$ plastic waste increased the conductivity of the materials, both during the day and night. A recommendation of plastic waste and rice husk or sawdust composition was to use a ratio of 40:60 or 60:40 which would reduce the outdoor air temperature of 0.8 to $0.9^{\circ} \mathrm{C}$ at daytime. Rice husk as the supporting materials would increase the porosity of the materials and absorb the outdoor air temperature. But this porosity would reduce the ability to store the outdoor air temperature.
\end{abstract}

Keywords Brick Composite, Plastic Waste, Rice Husk, Sawdust, Thermal Insulation

\section{Introduction}

The problem of plastic waste has been increasing every year in almost all countries in the world. Sadly, Indonesia is the second-largest contributor to plastic waste in the world [1]. Plastic waste is non-biodegradable so it has to be managed properly by reducing, reusing and recycling to avoid environmental degradation [2][3][4]. Efforts have been done to utilize plastic waste to become usable material. One of the most potential ways of managing plastic waste was into the field of building construction. Several studies to utilize plastic as an alternative material in the construction industry had been carried out before, for example for bricks [5][6][7][8][9] and concrete [10].

The previous researches concluded that the highest advantage of using plastic waste is because it has less weight compared to standard brick [5][6][7]. Moreover, Singhal and Netula [6] stated that the use of plastic waste in the innovation of brick had minimum water absorption, highly compressive strength, smooth surface, and unbreakable [9]. Amir and Yusof [8] also highlighted that producing brick from plastic waste would bring advantages of cost and functionality.

Plastic waste and other waste materials from agriculture, such as sawdust and rice husk, have the potential to be used as thermal insulation for energy efficient buildings [11][12]. Poonyakan et al. [13] found that plastic waste in high volume fraction would increase porosity but decrease its thermal conductivity. It is similar to the study of Oumaya et al. [14] finding that the thermal conductivity decreased with the increase of plastic waste aggregate 
within the composite, thus improving its insulation level. Waste materials from rice husk, wheat husk, wood fiber, and textile were potentially reused for sustainability and lower environmental impact [15]. Beside rice husk, other agriculture waste i.e. sawdust is also good for thermal insulation which can reduce outside heat flow significantly [16]. In the research of sawdust concrete by Memon et al. [17], the cement to sawdust ratio was prepared to be $1: 1,1: 2$, and 1:3. The research found that when the sawdust increased, it would reduce the heat transfer of sawdust cement.

This study aims to find the right composition of the use of plastic waste to become an alternative brick material as thermal insulation for the building. In this research, plastic waste was used as the main material which was combined with the use of other waste materials like sawdust and rice husk.

\section{Materials and Methods}

\subsection{Plastic Waste Brick Composite}

The material sample was made by mixing plastic waste material with sawdust or rice husk. The sawdust comes from the waste of teak wood (Tectona grandis), meanwhile the rice husk was taken from the rice mill in the agricultural area, both in Baki Sukoharjo and Central Java. These waste materials were added with Portland cement or white cement and used fox glue as an adhesive for the mixture. The experiment was conducted for a variety of mixture compositions to obtain some material samples with variations in the composition of different ingredients, see Figure 1 to Figure 4.

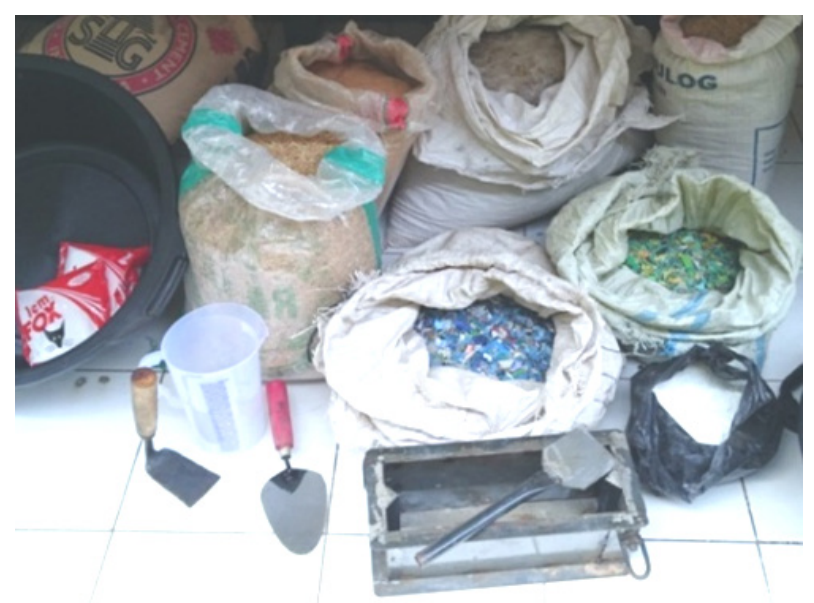

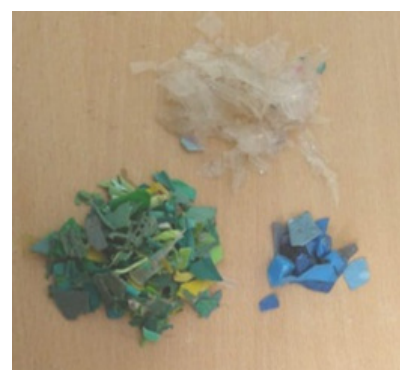

(a)

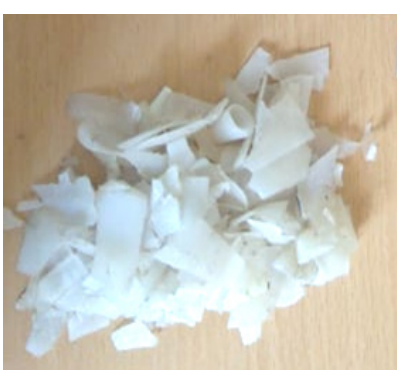

(b)

Figure 2. (a) HDPE (high-density polyethylene) plastic waste and (b) PP (polypropylene) plastic waste

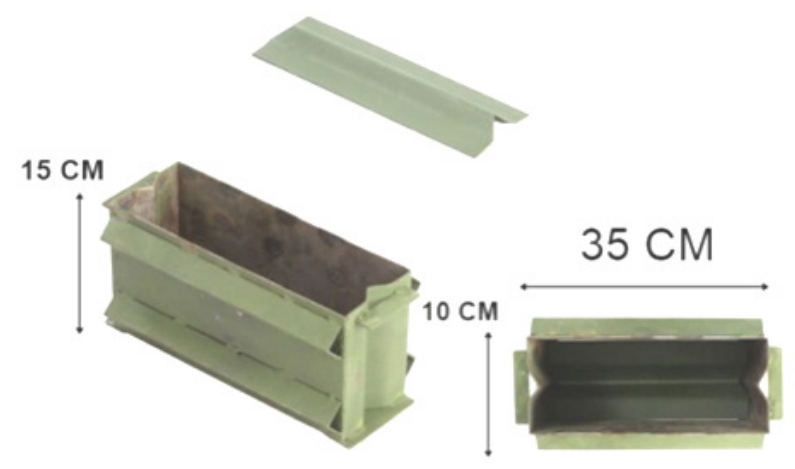

Figure 3. The brick mold

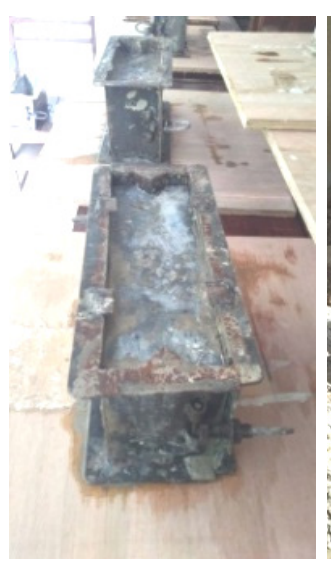

(a)

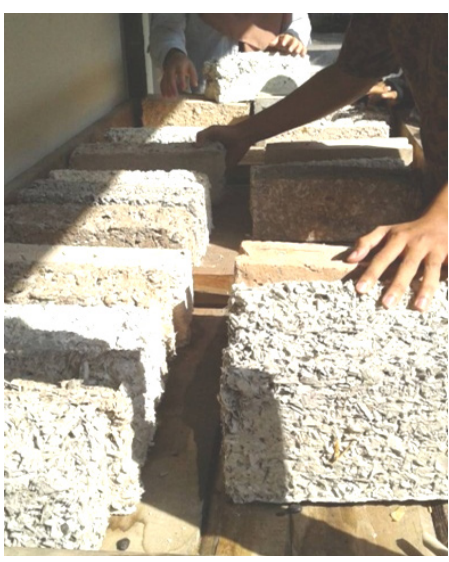

(b)

Figure 4. (a) The mixture of ingredients in the brick mold (b) The sample materials after drying

Material samples were shaped using brick molds to produce dimensions of samples that were compatible with conventional bricks. The composition of the core material mixture was plastic waste with sawdust or rice husk mixed with Portland cement or white cement obtained 20 samples of ingredients as shown in Table 1.

Figure 1. Tools and materials for making brick test materials from plastic waste 
Table 1. Composition of brick composite materials

\begin{tabular}{|c|c|c|c|c|c|}
\hline \multirow{2}{*}{ Sample \# } & \multicolumn{3}{|c|}{ Composite Materials (\%) } & \multicolumn{2}{|c|}{ Supporting Materials } \\
\hline & Plastic Waste & Rice Husk & Sawdust & Portland Cement & White Cement \\
\hline 1 & 70 & 30 & & $\sqrt{ }$ & \\
\hline 2 & 70 & 30 & & & $\sqrt{ }$ \\
\hline 3 & 70 & & 30 & $\sqrt{ }$ & \\
\hline 4 & 70 & & 30 & & $\sqrt{ }$ \\
\hline 5 & 30 & 70 & & $\sqrt{ }$ & \\
\hline 6 & 30 & 70 & & & $\sqrt{ }$ \\
\hline 7 & 30 & & 70 & $\sqrt{ }$ & \\
\hline 8 & 30 & & 70 & & $\sqrt{ }$ \\
\hline 9 & 60 & 40 & & $\sqrt{ }$ & \\
\hline 10 & 60 & 40 & & & $\sqrt{ }$ \\
\hline 11 & 60 & & 40 & $\sqrt{ }$ & \\
\hline 12 & 60 & & 40 & & $\sqrt{ }$ \\
\hline 13 & 40 & 60 & & $\sqrt{ }$ & \\
\hline 14 & 40 & 60 & & & $\sqrt{ }$ \\
\hline 15 & 40 & & 60 & $\sqrt{ }$ & \\
\hline 16 & 40 & & 60 & & $\sqrt{ }$ \\
\hline 17 & 50 & 50 & & $\sqrt{ }$ & \\
\hline 18 & 50 & 50 & & & $\sqrt{ }$ \\
\hline 19 & 50 & & 50 & $\sqrt{ }$ & \\
\hline 20 & 50 & & 50 & & $\sqrt{ }$ \\
\hline
\end{tabular}

\subsection{Thermal Measurement}

After 20 material samples had been made, preparations were made for thermal measurements. Thermal measurement was conducted by making a thermal chamber model on a scale of 1:5. The thermal chamber model made was $60 \times 60 \times 60 \mathrm{~cm}^{3}$ in size to represent the actual room measuring $3.00 \times 3.00 \times 3.00 \mathrm{~m}^{3}$. The model was made of coated glass so that it was equivalent to the conductivity properties of a brick wall. An opening which had wide as the sample materials was made to place the samples to be tested. Thermal measurements were carried out indoors and outdoors and measured simultaneously to see the differences between indoor and outdoor air temperatures.

The thermal measurement method was carried out as follows:

1. Calibrations were performed on both digital thermometers before being used for the measurements.

2. Measurements were conducted in an open space protected by the roof so that the air temperature was not affected by solar radiation.

3. The first thermometer sensor was placed in the thermal chamber model to measure indoor air temperature, see Figure 5; the second thermometer was placed outside to measure the outdoor air temperature.

4. Measurements were made on the 20 sample materials to see the ability of materials as heat insulation, see Figure 6.

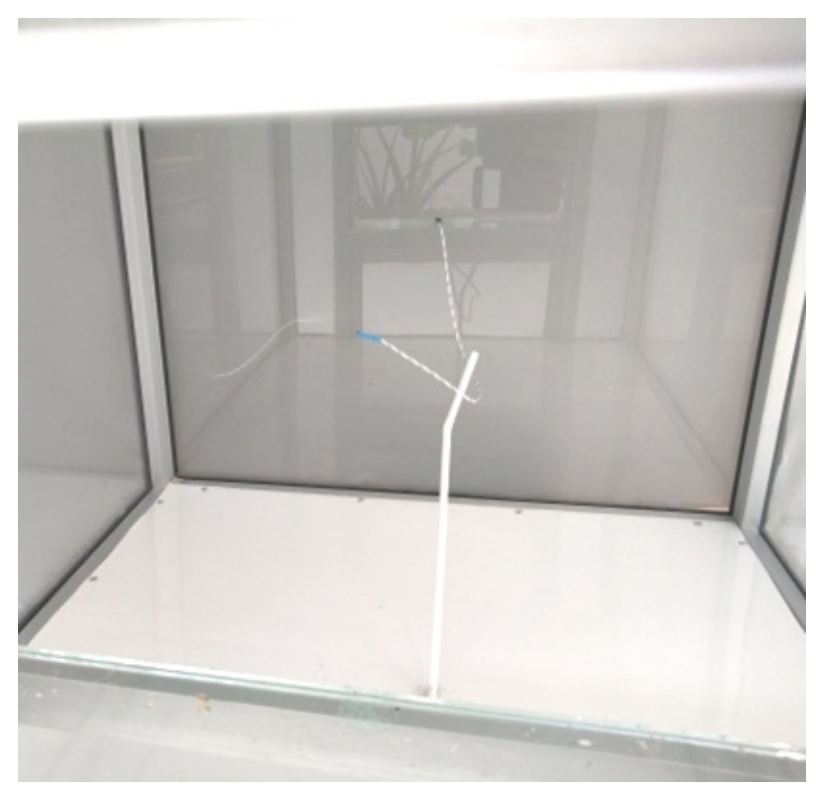

Figure 5. Thermal measurement in the thermal chamber model 


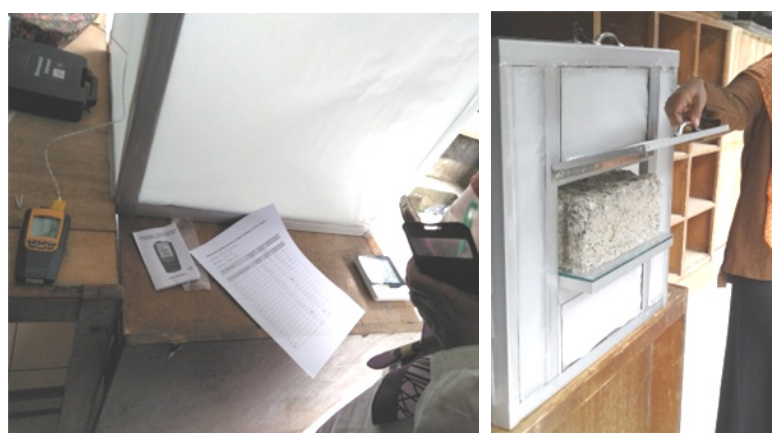

Figure 6. Material samples were placed in the opening of the thermal chamber model

\section{Results and Discussion}

Thermal measurements were carried out in May 2019 during the day and night. Daytime measurements started at 14:18 WIB during hot weather and clear skies. Meanwhile, night measurements were carried out starting at 21:30 WIB. The weather was clear and the air was cool. The results of thermal measurements at day and night were shown in Table 2.

The results of all thermal measurements showed that the temperature conditions during the day and night had quite large differences. The daytime measurements showed that the air temperature fluctuation was similar both inside and outside the thermal chamber model as shown in Figure 7. There were only slightly differences between indoor and outdoor temperatures. The indoor air temperature ranges from 30.8 to $31.6^{\circ} \mathrm{C}$. Meanwhile, outdoor air temperature fluctuation ranges from 31.3 to $32.1^{\circ} \mathrm{C}$. The difference between the minimum and maximum temperatures during the day was $0.8^{\circ} \mathrm{C}$ both for indoors and outdoors.

Meanwhile, the results of measurements of air temperature at night showed larger temperature fluctuation inside than outside the thermal chamber model. The outdoor air temperature was ranging from 27.3 to $27.6^{\circ} \mathrm{C}$ (the temperature difference was only $0.3^{\circ} \mathrm{C}$ ). Meanwhile, indoor air temperature was ranging from 22.2 to $23.6^{\circ} \mathrm{C}$, with a difference between minimum and maximum indoor air temperatures of $1.4^{\circ} \mathrm{C}$. This can be seen in Figure 8.

Thermal measurements of the sample materials carried out during the day clearly showed that the ratio of the composition of the materials that mostly used plastic waste $(70 \%)$ was not able to reduce the heat temperature from the outside. The supporting materials used (Portland cement or white cement) did not affect the difference significantly. A ratio of 70:30 composition of plastic waste and rice husk, either with Portland cement or white cement, had the lowest air temperature differences between outdoor and indoor, as well as the composition of 70:30 plastic waste and sawdust with Portland cement (Sample 1, 2, and 3). On the contrary, it actually added hot air in the room (Sample 1-3). The measurements on these three samples had shown that these composition materials increased the indoor air temperature as much as $0.1^{\circ} \mathrm{C}$ higher than outdoor air temperature.

An interesting result was found in the material composition of 60:40 between plastic waste and rice husk. This composition was able to reduce the outside air temperature by $0.9^{\circ} \mathrm{C}$ (Samples 9 and 10) resulting in cooler air temperatures in the room, see Figure 7. It was followed by the composition of plastic waste with sawdust in a ratio of $60: 40$ or $40: 60$, both of which were able to reduce the outside air temperature by $0.8^{\circ} \mathrm{C}$ either using Portland cement or white cement (Samples 11, 12, 15, and 16). It showed that a ratio of $60: 40$ or $40: 60$ of plastic waste and rice husk or sawdust was a good composition to reduce the outdoor air temperature during daytime compare to other composition.

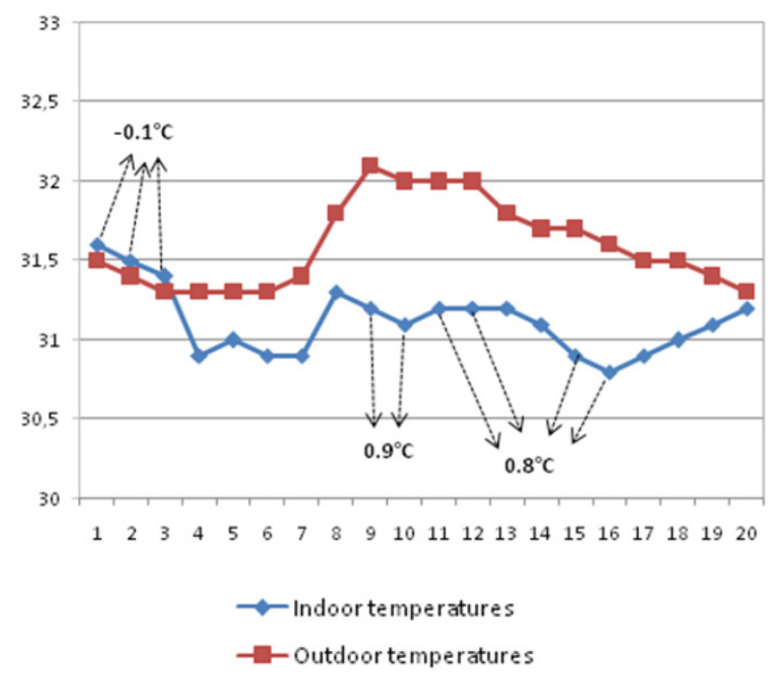

Figure 7. Results of Temperature Measurement at Daytime 
Table 2. Daytime and Night time Measurement

\begin{tabular}{|c|c|c|c|c|c|c|}
\hline \multirow[b]{2}{*}{ \# Sample } & \multicolumn{3}{|c|}{ Daytime Measurement } & \multicolumn{3}{|c|}{ Night time Measurement } \\
\hline & $\mathrm{T}$ in $\left({ }^{\circ} \mathrm{C}\right)$ & $\mathrm{T}$ out $\left({ }^{\circ} \mathrm{C}\right)$ & $\mathrm{T}$ out $-\mathrm{T}$ in $\left({ }^{\circ} \mathrm{C}\right)$ & $\mathrm{T}$ in $\left({ }^{\circ} \mathrm{C}\right)$ & T out $\left({ }^{\circ} \mathrm{C}\right)$ & $\mathrm{T}$ out $-\mathrm{T}$ in $\left({ }^{\circ} \mathrm{C}\right)$ \\
\hline 1 & 31.6 & 31.5 & -0.1 & 22.4 & 27.6 & 5.2 \\
\hline 2 & 31.5 & 31.4 & -0.1 & 22.5 & 27.5 & 5.0 \\
\hline 3 & 31.4 & 31.3 & -0.1 & 22.5 & 27.4 & 4.9 \\
\hline 4 & 30.9 & 31.3 & 0.4 & 22.4 & 27.4 & 5.0 \\
\hline 5 & 31.0 & 31.3 & 0.3 & 22.2 & 27.3 & 5.1 \\
\hline 6 & 30.9 & 31.3 & 0.4 & 22.8 & 27.3 & 4.5 \\
\hline 7 & 30.9 & 31.4 & 0.5 & 22.5 & 27.4 & 4.9 \\
\hline 8 & 31.3 & 31.8 & 0.5 & 22.7 & 27.3 & 4.6 \\
\hline 9 & 31.2 & 32.1 & 0.9 & 23.0 & 27.3 & 4.3 \\
\hline 10 & 31.1 & 32.0 & 0.9 & 22.7 & 27.3 & 4.6 \\
\hline 11 & 31.2 & 32.0 & 0.8 & 22.7 & 27.3 & 4.6 \\
\hline 12 & 31.2 & 32.0 & 0.8 & 22.7 & 27.3 & 4.6 \\
\hline 13 & 31.2 & 31.8 & 0.6 & 22.7 & 27.3 & 4.6 \\
\hline 14 & 31.1 & 31.7 & 0.6 & 22.7 & 27.3 & 4.6 \\
\hline 15 & 30.9 & 31.7 & 0.8 & 23.0 & 27.3 & 4.3 \\
\hline 16 & 30.8 & 31.6 & 0.8 & 23.0 & 27.3 & 4.3 \\
\hline 17 & 30.9 & 31.5 & 0.6 & 22.7 & 27.3 & 4.6 \\
\hline 18 & 31.0 & 31.5 & 0.5 & 23.6 & 27.3 & 3.7 \\
\hline 19 & 31.1 & 31.4 & 0.3 & 22.7 & 27.3 & 4.6 \\
\hline 20 & 31.2 & 31.3 & 0.1 & 23.3 & 27.3 & 4.0 \\
\hline
\end{tabular}

The results of thermal measurements carried out at night showed that the sample materials had an effect on reducing the air temperature in the room. The measurement results showed the largest decrease in outdoor air temperature when used the composition of plastic waste $70 \%$. Thermal measurements at night showed that 70:30 plastic waste and rice husk with Portland cement had the highest air temperature difference between outdoor and indoor air temperatures at $5.2^{\circ} \mathrm{C}$, see Figure 8. It was followed by a composition of 70:30 plastic waste and rice husk as well as 70:30 plastic waste and sawdust both with white cement; the indoor air temperature difference was $5^{\circ} \mathrm{C}$. The large percentage of plastic waste seemed to have an effect on reducing the outdoor temperature at night. However, a ratio of 30:70 plastic waste and rice husk with Portland cement had also reduced the outdoor air temperature significantly; the difference was $5.1{ }^{\circ} \mathrm{C}$. The character of rice husk was similar to plastic waste in terms of its light in weight and high porosity; the absorption of Portland cement might have increased its ability to reduce air temperature from outside.

The lowest decrease in outside air temperature occurred at night was in the composition of plastic waste material and rice husk with a ratio of 50:50 with white cement (Sample 18); the difference between outdoor and indoor air temperature was $3.7^{\circ} \mathrm{C}$. It is in line with research by
Haryati, Mohadi, \& Syah [18] revealing that rice husk granule had the lowest thermal conductivity. The sawdust waste as supporting materials had similar characteristics as rice husk in porosity which was favorable for thermal insulation [19].

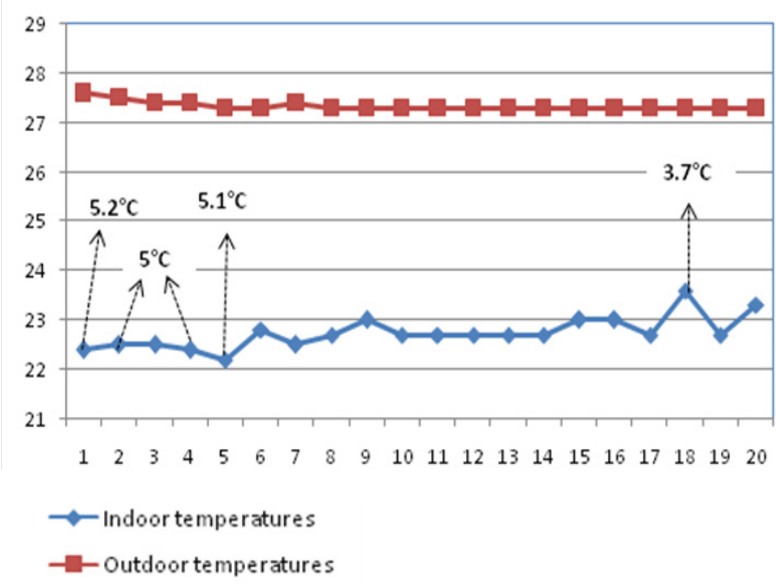

Figure 8. Results of Temperature Measurement at Night

The results of this study showed that the thermal composition of the plastic waste material with rice husk and sawdust had an ability to reduce the outdoor air temperature. This can be due to the very strong porosity characteristic of this composition of materials by using 
small pieces of plastic waste, combined with the use of rice husk and sawdust. The use of Portland cement and white cement had bonded all components so that they play a role in cooling the room. The exception was the composition of plastic waste when it was too high $(70 \%)$ during the day which would cause the air temperature indoor to increase. Plastic materials which had a smooth and massive surface were different from rice husk and sawdust, which had a naturally porous surface. These momentary thermal measurements at daytime and night time showed that the alternative materials composed by plastic waste and rice husk or sawdust had reduced outdoor air temperature more at night than in the daytime. The recommendation ratio for the material composition is $60: 40$ or $40: 60$, either with the addition of rice husk or sawdust. The temperature difference between the indoor and outdoor temperature ranges on this ratio was from 4.3 to $4.6^{\circ} \mathrm{C}$, which was the average reduction of air temperature at night.

The thermal measurements showed that plastic materials in small pieces which had smooth surface influenced the conductivity of the materials. It showed when the large percentage of plastic waste was used in the composition, both during the day and night that the outdoor air temperature would influence the indoor air temperature. These results were different from the results found by Poonyakan et al. [13] and Oumaya et al. [14]. Rice husk materials had the significant role to increase the porosity of the materials thus absorb the outdoor air temperature. However, this porosity characteristics had caused the ability to store the outdoor air temperature was reduced. Therefore, it is recommended for the future research to do a full-day thermal measurement to better understand the insulation characteristics of the materials.

\section{Conclusions}

This research can be concluded as follows:

- The composition that mostly used plastic waste (70\%) was not able to reduce the heat temperature at daytime. The measurement results at night showed that the composition with a ratio of $70 \%$ plastic waste reduced outdoor air temperature the most. It showed that plastic materials in small pieces might increase the conductivity of the composition materials, both during the day and night.

- A ratio of 60:40 or 40:60 of plastic waste and rice husk or sawdust was a good composition to reduce the outdoor air temperature during daytime compare to other composition.

- Rice husk in the composition materials had a significant role to increase the porosity of the materials and absorb the outdoor air temperature. However, this porosity might cause the ability to store the outdoor air temperature was reduced.
- For the future research, it is recommended that the thermal measurement extend to a full-day to be able to understand the insulation characteristics of the materials.

\section{Acknowledgments}

Our gratitude to the Doctoral Grant Research Program from LPPM Universitas Muhammadiyah Surakarta (UMS).

\section{REFERENCES}

[1] T. Wahyuni, Indonesia Penyumbang Sampah Plastik Terbesar Ke-dua Dunia, www.cnnindonesia.com, para. 1, Feb. 23, 2016. [Online]. Available: https://www.cnnindones ia.com/gaya-hidup/20160222182308-277-112685.

[Accessed: Oct. 21, 2019].

[2] P. Rajkumar, A Study on the Plastic Waste and Environmental Degradation, ABC Journal Advanced Research 4 No.1, 2015.

[3] F.L. Sahwan, D.H. Martono, S. Wahyono and L.A. Wisoyodharmo, Sistem Pengelolaan Limbah Plastik di Indonesia, Jurnal Teknik Lingkungan, P3LT-BPPT, 6 No.1: 311-318, 2005.

[4] P. Gupta, Management of Plastic Waste: A Step Towards Clean Environment, International Journal Renewable Energy Tech 8, Nos 3/4, 2017.

[5] L.M.F. Purwanto and A.M.S. Darmawan, Modelling of Plastic Waste as an Alternative Building Material in the Form of Brick, International Journal of Advanced Engineering and Management Research 2, Issue 3, 2017.

[6] A. Singhal and O. Netula, Utilization of Plastic Waste in Manufacturing of Plastic Sand Bricks, JETIR 5, Issue 6, 2018.

[7] S. Shrimali, Bricks from Waste Plastic, International Journal Advanced Research (IJAR) 5, Issue 1, pp. 2839-2845, 2017.

[8] S.N. Amir and N.Z. Yusof, Plastic in Brick Application, Trends in Civil Engineering and Architecture, 2018.

[9] A. Daftardar, P. Rashmi, R. Shah, P. Gandhi and H. Garg, Use of Waste Plastic as a Construction Material, International Journal Engineering and Applied Science (IJEAS) 4, Issue 11, 2017.

[10] M.A. Kamaruddin, M.M.A. Abdullah, M.H. Zawawi and M.R.R.A. Zainol, Potential Use of Plastic Waste as Construction Materials: Recent Progress and Future Prospect, IOP Conference Series: Materials Science and Engineering p.267, 2017.

[11] M. Vasilache, M. Pruteanu and C. Avram, Use of Waste Materials for Thermal Insulation in Buildings, Environmental Engineering and Management Journal 9, No. 9, pp. 1275-1280, 2010. 
[12] K. Ragaert, L. Dela and K. van Geem, Mechanical and Chemical Recycling of Solid Plastic Waste, Waste Management, 2017.

[13] A. Poonyakan, M. Rachakornkij, M. Wecharatana and W. Smittakorn, Potential Use of Plastic Wastes for Low Thermal Conductivity, Concrete Materials 11, 1938; doi: 10.3390/ma11101938, 2018

[14] Y.M. Oumaya, D. Rose-Marie, L. Boubker, Q. Michele, Valorisation of Plastic Waste: Thermal Conductivity of Concrete Formulated with PET,Wasteeng Conference at Albi France, 2005.

[15] R. Muthuraj, C. Lacoste, P. Lacroix and A. Bergeret, Sustainable Thermal Insulation Biocomposites from Rice Husk, Wheat Husk, Wood Fibers and Textile Waste, Fibers: Elaboration and Performances Evaluation Industrial Crops \& Products 135, pp. 238-245, 2019.
[16] Ismail, Mardiani, D. Lismayani and Fauzi, Sawdust for Thermal Insulation Building, Proceedings of the $2^{\text {nd }}$ International Conference on Natural and Environmental Science (ICONES), 2014.

[17] R.P. Memon, Mohd Sam, A.S.M.A. Awal and L. Achekzai, Mechanical and Thermal Properties of Sawdust Concrete, JurnalTeknologi (Science and Engineering), 79:6, pp. 23-27, 2017.

[18] S. Haryati, R. Mohadi and K. Syah, Insulation Material from Rice Husk Granule, Chemical Engineering Transaction 56, 2017.

[19] S.K.S. Hossain, A. Bhardwaj and M.R. Majhi, Preparation and Characterization of Insulating Rice Husk Ash Refractory using Rice Husk as Pore Forming Agent, International Journal Science and Research (IJSR) 5, Issue 2, 2016 . 